\title{
ANALYSIS OF STABILITY OF THE ROTOR ANGLE IN ENERGY PRODUCTION SYSTEMS
}

\section{OSCAR FLÓREZ-CEDIEL, ANDRÉS JUTINICO-ALARCÓN \& JULIÁN R. CAMARGO L}

Engineering Faculty, Universidad Distrital Francisco José de Caldas, Bogotá, Colombia

\begin{abstract}
This paper analyzes the rotor angle stability of a typical infinity bar system for a power generation plant using the PhillipsHeffron model. Subsequently, a power system stabilizer is incorporated to obtain mechanical and electrical damping to maintain synchronism in its operation and control of the rotor angle. With these models,we can better understand its operation and establish the conditions to minimize disturbances and improve response instability. The simulations were carried out in the computer tool Matlab.
\end{abstract}

KEYWORDS: Phillips-Heffron Model, Power System Stabilizer-PSS, Rotor Angle Stability \& Small-Signal Analysis

Received: Jun 08, 2020; Accepted: Jun 28, 2020; Published: Sep 11, 2020; Paper Id.: IJMPERDJUN20201164

\section{INTRODUCTION}

Power generation systems are very complex mechanisms that are affected by events such as changes in loads, mechanical disturbances, failures in the associated substation and output lines, changes in the parameters of the system's elements, among others; for which plant operators must take actions that guarantee a reliable and good quality service for as long as possible. With the increase of distributed generation systems, it is essential to analyze the operation and the events that may occur at some point and affect the service provision.

Power systems constantly experience small power oscillations that do not lead to system instability. The oscillations occur when generator rotors are accelerated or decelerated to balance electrical power output with mechanical power input to respond to changes in demand or system topology. Power stability analyses determine the application and operation of elements that generate equal or higher and opposite forces to the disturbance causing an unbalance of the system that leads to an alteration of the normal working state [1].

The stability of a power generation system contemplates the analysis of the rotor angle, signal frequency and voltage parameters. In the operation of power systems, problems of insufficient damping of oscillations have been detected, which can be local or inter-area[2], [3]. The first is associated with the oscillation of units in a generation station concerning the rest of the system, and the second, to the oscillation of a group of machines against another group of machines [4]-[8].

Frequency control is a balance between generation and demand. The generation is affected by the power delivered and the supply schedule. On the other hand, the demand considers loads that changing in time, associated losses and scheduled sales [9]. To reduce the effects presented by the disturbances, Power System Stabilizers (PSS) are used, whose basic function is to generate an auxiliary signal to the machine's excitation system when rotor oscillations exceeding predetermined values occur [10]-[12]. 


\section{SMALL-SIGNAL ANALYSIS IN POWER SYSTEMS}

Small-signal stability is the ability of a power system to maintain synchronism when subjected to small disturbances. A disturbance is small if the dynamic equations describing the system response can be linearized for analysis, for example, a change in the gain of the automatic voltage regulator (AVR) [13]-[15]. A power system considers multiple variables dependent on several elements each with different characteristics. For stability analysis, the system topology, type of disturbance and operating conditions among others must be considered.

Rotor angle stability is associated with small-signal and transient stability disturbances. In terms of frequency stability two intervals are considered, the first goes from zero to ten seconds (Short Term) and the second from a few minutes to ten minutes in some cases (Long Term).

Voltage stability requires keeping the voltage ratings constant with the changes in the load connected to the system, including the dynamics of the reactive energy at all times [16].

In the stability analysis of power systems, they are usually modeled with a machine with a constant internal voltage value, infinite inertia and an ideal impedance equal to zero. This is known as an infinite busbar, considering also that it connects the power system (high-voltage lines, transformers, etc.) to the generator as shown in Figure 1.

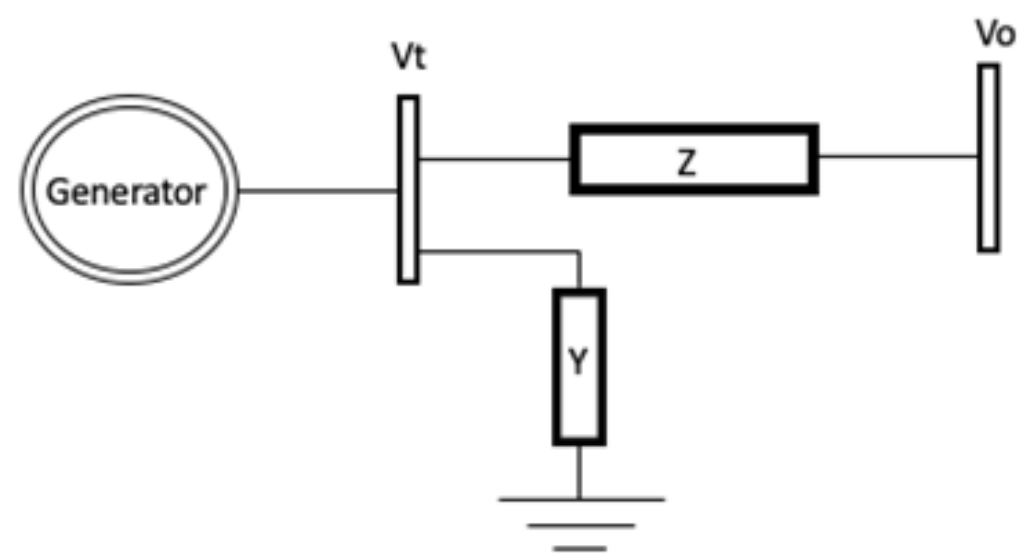

Figure 1: Infinite Bus Machine.

Where:

$V_{t}$ is the line input voltage

$Z$ is the line impedance

$V_{o}$ is the line output voltage

$Y$ is the grounding impedance [17].

The infinite busbar condition is to ensure that there are no voltage drops under any circumstances.

The Phillips-Heffron model considers four basic constants $\left(k_{1}, k_{2}, k_{3}\right.$ and $\left.k_{4}\right)$ for the machine's field circuit, which is presented in Figure 2 [18]. 


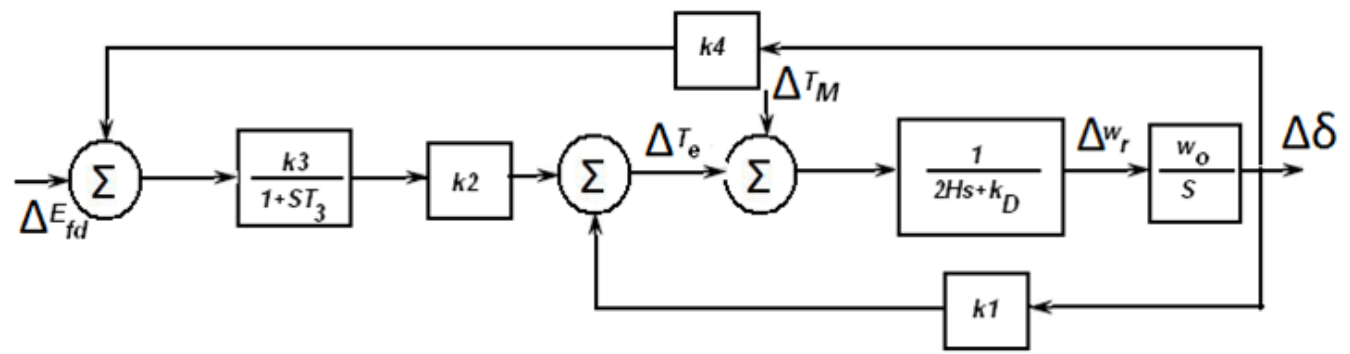

Figure 2: Block Diagram Field Circuit.

The constant $k_{l}$ represents the coefficient of synchronized torque and is determined by the following expression (1).

$k_{1}=\cos \left(\delta_{0}\right)\left[\frac{V_{t q 0} V_{b}}{X_{q T}}\right]+\sin \left(\delta_{0}\right)\left[\frac{X_{q}-X_{d}^{\prime}}{X_{d}^{\prime}+\frac{1}{2}\left(R_{S}+R_{R}\right)}\right] i_{q 0} V_{b}$

Where:

$\delta_{0}$ is the initial angle

$V_{t q 0}$ is the quadrature axis armature voltage

$V_{b}$ is the infinite busbar voltage

$X_{q T}$ is the quadrature axis armature reactance

$X_{q}$ is the q-axis synchronous reactance

$X_{d}^{\prime}$ is the d-axis transient reactance

$R_{S}$ is the stator resistance

$R_{R}$ is the rotor resistance

$i_{q 0 \text { is }}$ the initial quadrature current.

The constant $k_{2}$ relates the variations in the field flow with the variation in the electric torque by (2).

$k_{2}=\sin \left(\delta_{0}\right)\left[\frac{V_{b}}{x_{d}^{\prime}+\frac{1}{2}\left(R_{S}+R_{R}\right)}\right]$

The constant $k_{3}$ determines the impedance factor usingexpression (3).

$k_{3}=\frac{X_{d}^{\prime}+\frac{1}{2}\left(R_{S}+R_{R}\right)}{X_{d}+\frac{1}{2}\left(R_{S}+R_{R}\right)}$

Where $X_{d}$ is the synchronous reactance of the d-axis.

The change in field-flow due to changes in load angle is described by the constant $k_{4}$ in (4).

$k_{4}=\sin \left(\delta_{0}\right)\left[\frac{X_{d}-X_{d}^{\prime}}{X_{d}^{\prime}+\frac{1}{2}\left(R_{S}+R_{R}\right)}\right] V_{b}$

Two additional constants are taken into account when adding an excitation system and an AVR to the machine, as shown in Figure 3 [1]. 


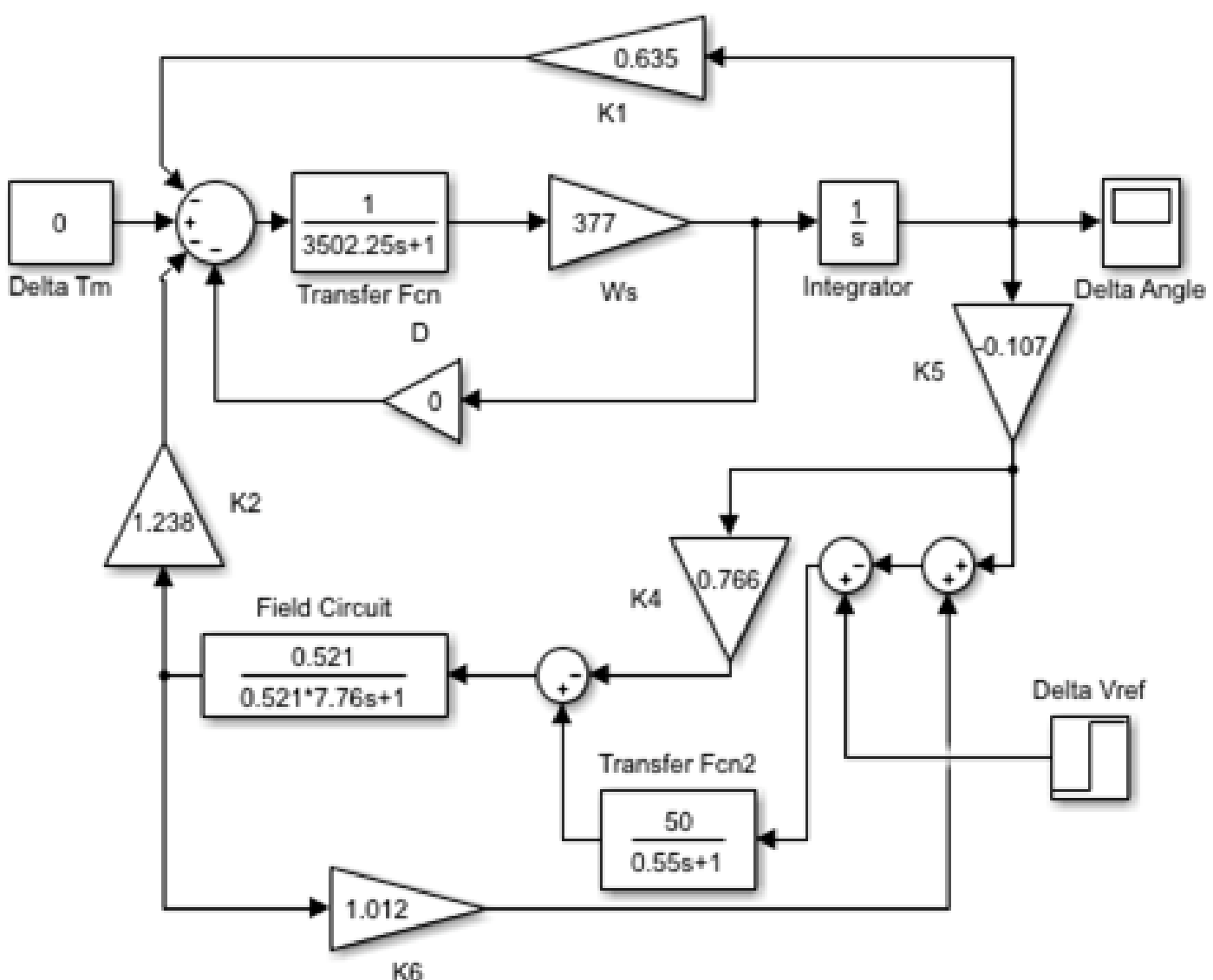

Figure 1: Block Diagram of the System Machine Infinite Busbar.

In the expressions, (5) and (6) are presented the mathematical models of the constants $k_{5}$ and $k_{6}$ respectively.

$$
\begin{aligned}
& k_{5}=\cos \left(\delta_{0}\right)\left[\frac{X_{q} V_{d 0}}{X_{q T} V_{t 0}}\right] V_{b}-\sin \left(\delta_{0}\right)\left[\frac{V_{q 0} X_{d}^{\prime}}{V_{t 0}\left(X_{d}^{\prime}+\frac{1}{2}\left(R_{S}+R_{R}\right)\right.}\right] V_{b} \\
& k_{6}=\frac{V_{q 0}\left[\frac{1}{2}\left(R_{S}+R_{R}\right)\right]}{V_{t 0}\left[X_{d}^{\prime}+\frac{1}{2}\left(R_{S}+R_{R}\right)\right]}
\end{aligned}
$$

Where additionally the variables $V_{d 0}$ is the initial voltage on the $d$ axis, $V_{t 0}$ is the initial armature voltage, $V_{q 0}$ is the initial voltage on the $q$ axis.

Replacing the values of the constants presented in Table 1, the delta response of the angle is obtained, which is presented in Figure 4 [19], [20].

Table 1:Values of the Model Constants Phillips-Heffron System Under Study

\begin{tabular}{|l|c|c|c|c|c|c|}
\hline Constant & $\boldsymbol{k}_{\boldsymbol{1}}$ & $\boldsymbol{k}_{2}$ & $\boldsymbol{k}_{3}$ & $\boldsymbol{k}_{4}$ & $\boldsymbol{k}_{5}$ & $\boldsymbol{k}_{6}$ \\
\hline Value & 0,635 & 1,238 & 0,657 & 0,766 & $-0,107$ & 1,012 \\
\hline
\end{tabular}




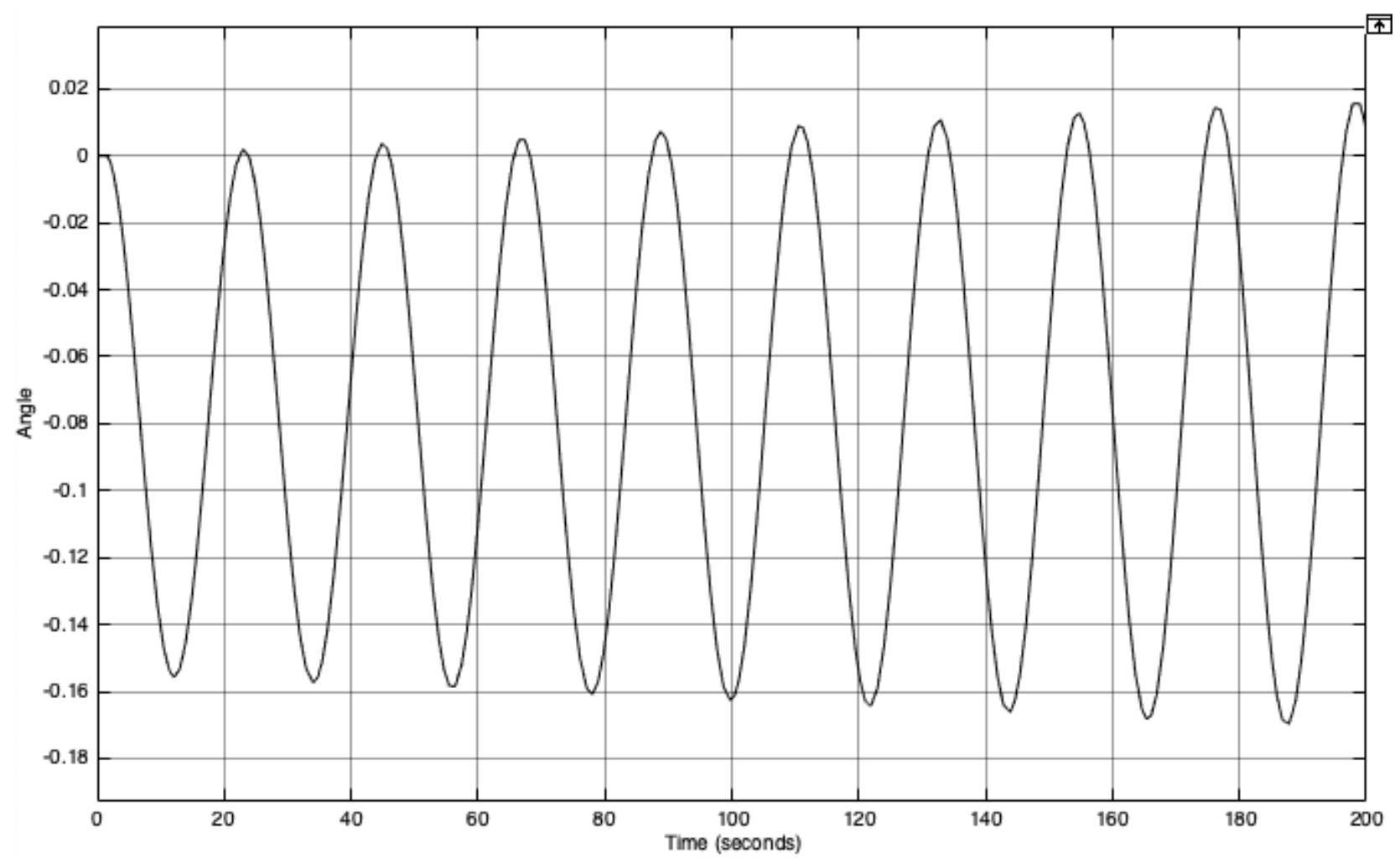

Figure 2: System Response to Changes in the Reference Voltage.

The equations of state that represent the system are presented below

$\left[\begin{array}{c}\Delta \dot{E}_{q}^{\prime} \\ \Delta \dot{\delta} \\ \Delta \dot{V}\end{array}\right]=\left[\begin{array}{ccc}\frac{-1}{k_{3} T_{d 0}^{\prime}} & \frac{-k_{4}}{T_{d 0}^{\prime}} & 0 \\ 0 & 0 & w_{s} \\ \frac{-k_{2}}{2 H} & \frac{-k_{1}}{2 H} & \frac{-D w_{s}}{2 H}\end{array}\right]\left[\begin{array}{c}\Delta E_{q}^{\prime} \\ \Delta \delta \\ \Delta V\end{array}\right]+\left[\begin{array}{c}\frac{1}{T_{d 0}^{\prime}} \\ 0 \\ 0\end{array}\right] \Delta E_{f d}$

To find the solution, the following matrix system is considered.

$$
\left[\begin{array}{c}
\Delta \dot{E}_{q}^{\prime} \\
\Delta \dot{\delta} \\
\Delta \dot{V}
\end{array}\right]=[A]\left[\begin{array}{c}
\Delta E_{q}^{\prime} \\
\Delta \delta \\
\Delta V
\end{array}\right]+[B]
$$

Matrixes A and B are described by the following expressions

$$
A=\left[\begin{array}{ccc}
\frac{-1}{k_{3} T_{d 0}^{\prime}} & \frac{-k_{4}}{T_{d 0}^{\prime}} & 0 \\
0 & 0 & w_{s} \\
\frac{-k_{2}}{2 H} & \frac{-k_{1}}{2 H} & \frac{-D w_{S}}{2 H}
\end{array}\right] B=\left[\begin{array}{c}
\frac{1}{T_{d 0}^{\prime}} \\
0 \\
0
\end{array}\right]
$$

Replacing the values of the constants to find the values of the arrays A and B

$$
A=\left[\begin{array}{ccc}
-0,196 & -0,1 & 0 \\
0 & 0 & 377 \\
-3,5 \times 10^{-4} & -1,8 \times 10^{-4} & 0
\end{array}\right] B=\left[\begin{array}{c}
0,129 \\
0 \\
0
\end{array}\right]
$$

Therefore, the expressions of ratio change for voltage, frequency and angle are

$$
\Delta \dot{E}_{q}^{\prime}=-0,196 \Delta E_{q}^{\prime}-0,1 \Delta \delta+0,129 \Delta E_{f d}
$$


$\Delta \dot{\delta}=377 \Delta V$

$\Delta \dot{V}=-0,00035 \Delta E_{q}^{\prime}-0,00018 \Delta V$

The mechanical and electrical modes are defined by the values of the matrix presented below in (10).

$$
\left[\begin{array}{cccc}
0 & \frac{-k_{1}}{M} & \frac{-k_{2}}{M} & 0 \\
w_{s} & 0 & 0 & 0 \\
0 & \frac{-k_{4}}{T_{d 0}^{\prime}} & \frac{-1}{k_{3} T_{d 0}^{\prime}} & \frac{1}{T_{d 0}^{\prime}} \\
0 & \frac{-k_{a} k_{5}}{T_{a}} & \frac{-k_{a} k_{6}}{T_{a}} & \frac{1}{T_{a}}
\end{array}\right]
$$

Replacing with the corresponding values, the following matrix is proposed:

$$
\left[\begin{array}{cccc}
0 & -0,07 & -0,13 & 0 \\
377 & 0 & 0 & 0 \\
0 & -0,1 & -0,2 & 0,13 \\
0 & 9,7 & -92 & -1,8
\end{array}\right]
$$

Finally obtaining the mechanical modes in rows 1 and 2 and the electrical modes in rows 3 and 4 .

$$
\left[\begin{array}{c}
0,18+4,72 i \\
0,18-4,72 i \\
-1,2+3,9 i \\
-1,2-3,9 i
\end{array}\right]
$$

\section{SUPPLEMENTARY CONTROL SYSTEM}

To keep the system under control in the event of small-signal disturbances, a PSS is incorporated into the model so that damping is achieved in the mechanical model. Figure 5 shows a derivative mode PSS with feedback, which is applied to the system under study [1].

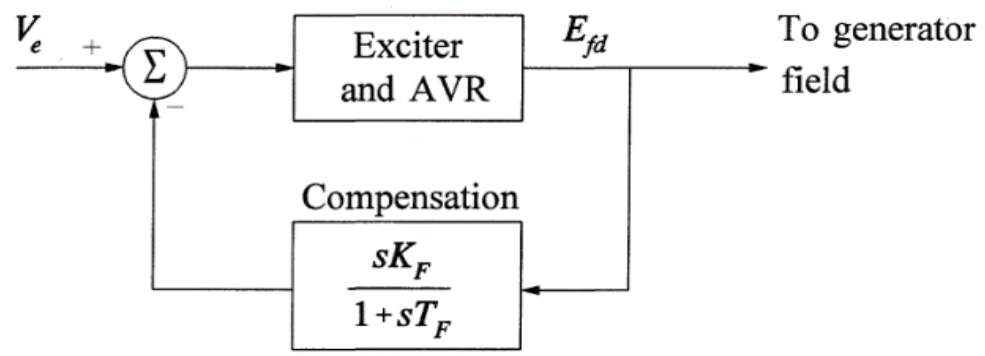

Figure 5: PSS Derivative with Feedback.

Incorporating the PSS as shown in figure 6, the control of the angle signal is obtained within particular parameters as shown in figure 7 . 


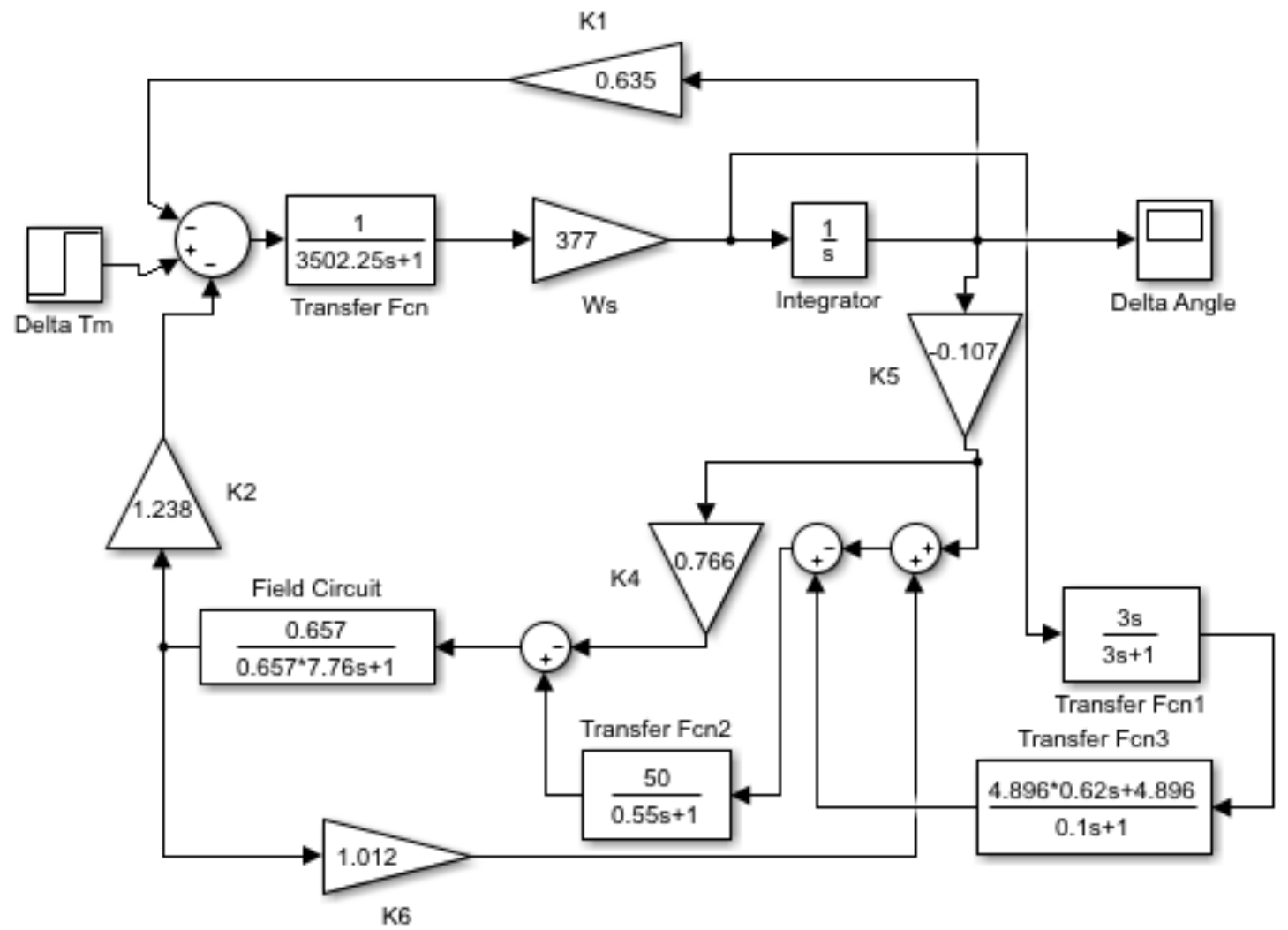

Figure 6: Block Diagram of the Infinite Busbar System with PSS.

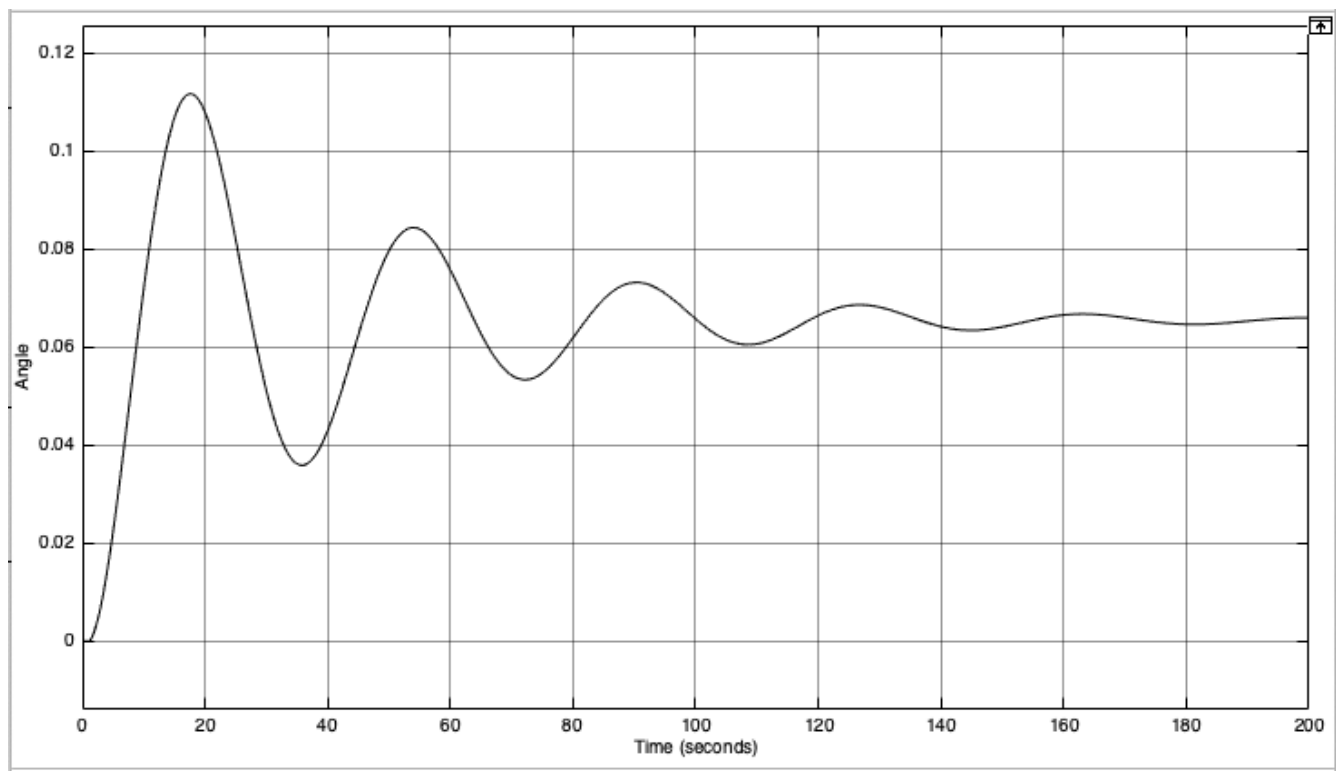

Figure 7: System Response to Changes in Reference Voltage with PSS.

\section{CONCLUSIONS}

The angle of the rotor without PSS presents great changes in its amplitude during a great interval of time, which causes mechanical efforts that diminish the useful life of the generation system, affecting the output signal and the synchronization with the transmission system.

The built-in PSS managed to stabilize the angle of the rotor with small signal disturbances satisfactorily in a time interval of 
$250 \mathrm{~s}$, which guarantees stable operation of the generation system.

It is important to incorporate to the stability of distributed generation systems the impact of electronic loads to determine the variables that can be most affected and how this modifies the operation of the system.

\section{ACKNOWLEDGMENTS}

The authors would like to thank the Universidad Distrital Francisco José de Caldas and the LASER research group that supported the development of the project.

\section{REFERENCES}

1. Kundur, P. (2017). Power system stability and control. London, UK: CRC Press.

2. Moreno-Chuquen, R. \&Florez-Cediel, O., Online Dynamic Assessment of System Stability in Power Systems Using the Unscented Kalman Filter, (2019) International Review of Electrical Engineering (IREE), 14 (6):465-472.

3. ALShamli, Y., Hosseinzadeh, N., Yousef, H. \& Al-Hinai, A. (2015). A review of concepts in power system stability. 2015 IEEE 8th GCC Conference \& Exhibition, Muscat, 2015, pp. 1-6.

4. Joshi, Jyoshna, and Onkar Sonare. "Optimisation of Wire EDM ProcessParameterson D3 Tool Steel using Principal ComponentAnalysis." International Journal of Mechanical and ProductionEngineeringResearch and Development (IJMPERD) 7.2 (2013): 31-40.

5. Sun, D., Li, Y., Wang, Q., Luo, Y., Liu, H., \&Zhao, F. (2020). Impact of Virtual Synchronous Generators on Inter-Area LowFrequency Oscillation. 2020 5th Asia Conference on Power and Electrical Engineering (ACPEE), Chengdu, China, 2020, pp. 498-502.

6. Mohammed, O. O., Otuoze, A. O., Salisu, S., Ibrahim, O. \&Rufa'i, N. A. (2019). Virtual synchronous generator: an overview. Nigerian Journal of Technology (NIJOTECH). 38(1):153-164.

7. Kumar, Rohit, and Sukhwinder Singh. "Comparativeanalysis of wavelet basedcompressionmethods." International journal of computernetworking, wireless and mobilecommunications (2014): 143-150.

8. Driesen, J. \&Visscher, K. (2018). Virtual synchronous generators. 2008 IEEE Power and Energy Society General Meeting Conversion and Delivery of Electrical Energy in the 21st Century, Pittsburgh, PA, 2008, pp. 1-3

9. Pimprikar, T., Pawaskar, O. \& Kumar, A. (2018). Virtual Synchronous Generator- A New Trend in Technology for Smart Grid Integration. 2018 International Conference on Information, Communication, Engineering and Technology (ICICET), Pune, India, 2018, pp. 1-5.

10. Ravindra, G. \&Chengaiah, CH. (2020). Fuzzy Logic Control for VSGs in Microgrid with Different Capacities of DGs. International Journalof Advanced Science and Technology. 29(4):826-839.

11. Rindhe, Baban U., Kanchan A. Hambarde, and S. K. Narayankhedkar. "Performance analysis of optical OFDM systemusing PM." International Journal of Electrical and ElectronicsEngineeringResearch 4.2 (2014): 307-316.

12. North American Electric Reliability Corporation - NERC, (2011). Balancing and Frequency Control.

13. Rangel P., C. (2005). Diseño y simulación de un controladordifuso multivariable centralizado para la estabilidad de un sistema de potenciamultiárea. Trabajo de grado. Bogotá. Universidad de los Andes, 47 p.

14. Yousef, H. A., Al Kharusi, K. Albadi, M. H. \&Hosseinzadeh, N. (2014). Load Frequency Control of a Multi-Area Power System: An Adaptive Fuzzy Logic Approach. Power Systems. IEEE Transactions on Power Systems. 29(4):1822-1830. 
15. Tungadio, D. H. \& Sun, Y. (2019). Load frequency controllers considering renewable energy integration in power system. Energy Reports. 5:436-453.

16. Shunmugasundaram, M., A. PraveenKumar, and D. Maneiah. "An experimental analysis and processparameteroptimizationonfrictionstirweldeddissimilaralloys." International Journal of Mechanical and ProductionEngineeringResearch and Development, 9 (2) (2019): 407-414.

17. Suganya R., Balaji B., \&Gayathri D.(2020). Load Modeling Using Anfis Tool in Voltage Stability Studies for 6 Bus and 30 Bus System. International Journal of Mechanical and Production Engineering Research and Development (IJMPERD).10(3):62916300 .

18. Mangera, P., Sumbung, F. H. \&Parenden, D. (2018). Automatic Voltage Regulator (AVR) Controller Design Based on Routh's Crution Stability Analysis in Diesel-Based Power Plants. In Proceedings of the International Conference on Science and Technology (ICST 2018). pp. 545-553.

19. Gunadin, I. C. Suyuti, A., Muslimin, Z., Ilyas, A. M. \&Siswanto, Agus. (2019). Control Design of AVR (Automatic Voltage Regulator) to Improve the Voltage Stability at Power Plant Sector Tello - PT.PLN (Persero) Region Sulselbar. The 3rd EPI International Conference on Science and Engineering 2019 (EICSE2019). Unhas, Indonesia.

20. Grainger, J.\& Stevenson, W.(1994). Power system analysis. New York: McGraw-Hill.

21. Sauer, P. W., Pai, M.A.\& Chow, J. H.(2017). Power system dynamics and stability: With Synchrophasor Measurement and Power System Toolbox. 2nd ed. Wiley-IEEE Press.

22. Torres, A. (2008). Control y estabilidad de sistemas de potencia. Apuntes de clase. Universidad de los Andes.

23. Sánchez, J. \&Umbarila, D.(2008). Herramienta de ayuda para el Análisis Modal en la evaluación de Estabilidad de Voltaje. Proyecto final Curso Control y Estabilidad de Sistemas de Potencia. Universidad de Los Andes.

24. Gurrala, G. \& Sen, I. (2008). A Modified Heffron-Phillip's Model for The Design of Power System Stabilizers. 2008 Joint International Conference on Power System Technology and IEEE Power India Conference, New Delhi, 2008, pp. 1-6. 
